Neuroepidemiology 2015;44:64-65

DOI: $10.1159 / 000373925$

\section{Relationship between Neurological Disorders and Heart Disease: A National Population Health Survey}

Jacquelyn J. Cragg a, b, John K. Kramer ${ }^{\mathrm{b}, \mathrm{c}}$, Jaimie F. Borisoff ${ }^{\mathrm{b}, \mathrm{d}}$

aSchool of Population and Public Health, Faculty of Medicine, University of British Columbia, Vancouver, B.C., ' International Collaboration on Repair Discoveries (ICORD), University of British Columbia, Vancouver, B.C., 'School of Kinesiology, University of British Columbia, Vancouver, B.C., Canada; ${ }^{\mathrm{d}}$ British Columbia Institute of Technology (BCIT), Burnaby, B.C., Canada

\section{Introduction}

There appears to be an increased risk of cardiovascular disease (CVD) among individuals with spinal cord injury [1-3]. Quantitative data concerning the risk of heart disease among individuals with other neurological disorders (NDs) are not available. Our aim was to estimate the prevalence of heart disease among individuals with NDs and to compare their risk with a control group.

\section{Methods}

We utilized data from the cross-sectional Canadian Community Health Survey (CCHS), as previously described $[2,4,5]$. The CCHS covers the population consisting of individuals 12 years of age and over living in the ten provinces and the three territories, and represents more than 100 health regions across Canada. Excluded from the survey's coverage are persons living on reserves, full-time members of the Canadian Forces, and institutionalized persons. Altogether, these exclusions represent less than $3 \%$ of the target population. The primary outcome variable was self-reported heart disease. The heart disease variable was selected as an overall reflection of cardiovascular health. The primary explanatory variable was a composite variable of self-reported neurological conditions (described in table 1 legend); Statistics Canada provides only grouped (composite) variables for some health conditions to protect the anonymity of individual respondents. Logistic regression models were developed, incorporating probability weighting to account for the CCHS sampling design. Multivariable models included covariates (also listed in table 1 legend) strongly associated with adverse cardiovascular profiles (e.g., Framingham risk scores) $[6,7]$. Reported percentages are also probability weighed. A bootstrapping method for variance estimation for complex survey data was utilized [5]. Ethical approval for the use of the data was obtained via the publicly available data clause from the University of British Columbia.

\section{KARGER 125}

2015 S. Karger AG, Base

0251-5350/15/0441-0064\$39.50/0

E-Mail karger@karger.com

www.karger.com/ned
Table 1. Odds ratios (95\% confidence intervals) for heart disease

\begin{tabular}{llll}
\hline Variable & $\begin{array}{l}\text { Unadjusted OR } \\
\text { heart disease } \\
(95 \% \mathrm{CI})\end{array}$ & $\begin{array}{l}\text { Age and sex-adjusted } \\
\text { OR heart disease } \\
(95 \% \mathrm{CI})\end{array}$ & $\begin{array}{l}\text { Fully Adjusted** } \\
\text { OR heart disease } \\
(95 \% \mathrm{CI})\end{array}$ \\
\hline \multicolumn{2}{l}{ Neurological disorder $(\mathrm{ND})^{\dagger}$} \\
$\mathrm{Yes}$ & $1.74(1.58,1.90)$ & $2.09(1.89,2.31)$ & $1.97(1.77,2.19)$ \\
$\mathrm{No}^{\ddagger}$ & 1.00 & 1.00 & 1.00
\end{tabular}

Odds ratios derived from logistic regression models (incorporating probability weighting). Both unadjusted and adjusted odds ratios (from multivariable analyses) are reported. ${ }^{\ddagger}$ Reference Category; $\mathrm{CI}=$ confidence interval; $\mathrm{OR}=$ odds ratio. ${ }^{* *}$ Also adjusted for smoking status, physical activity, alcohol consumption, body mass index and comorbiditities (Type 2 diabetes, hypertension, depression) in addition to sex and age. ${ }^{\dagger}$ Neurological disorders excluded mental health conditions and spinal cord injury, and included multiple sclerosis, epilepsy, cerebral palsy, spina bifida, hydrocephalus, muscular dystrophy, dystonia, Tourette's syndrome, migraine headaches, Parkinson's disease, amyotrophic lateral sclerosis, Huntington's disease, stroke, brain injury, brain tumor, Alzheimer's Disease or any other dementia.

\section{Results}

The final study sample included 60,343 individuals (49\% male; median age category $40-44$ years). There were a total of 8,368 unique individuals with an ND; this yielded a (weighted) prevalence of $13.39 \%$ for NDs. Among the total sample, the prevalence of heart disease was $4.89 \%$. Among individuals with an ND, the prevalence of heart disease was $7.53 \%$ compared to $4.48 \%$ in individuals without an ND.

Table 1 provides unadjusted and adjusted odds ratios (ORs) for heart disease. The odds of heart disease were 1.74 times greater in individuals with an ND versus individuals without an ND (95\% CI $1.58,1.90)$. After adjusting for sex and age, the heightened odds increased; the sex/age adjusted OR for heart disease was 2.09 (95\% CI $1.89,2.31$ ). After adjusting for all confounders (listed in the table legend), the fully adjusted OR for heart disease was 1.97 (95\% CI $1.77,2.19)$. Excluding individuals who had experienced a stroke, the sex/age adjusted OR for heart disease was 1.72 (95\% CI 1.52, 1.94).

\section{Discussion}

The present study utilized a comprehensive national survey with data collected from over 60,000 individuals to investigate the relationship between NDs and heart disease. Here, we demonstrate for the first time in a large, representative population that NDs are independently associated with significantly increased odds of heart disease. The heightened odds persist when excluding individuals with stroke. Moreover, we show for the first time that the association is independent of several known risk factors for CVD. This is important irrespective of whether NDs cause CVD, or alternatively, CVD causes neurological disorders; and indeed, the direction of causality may depend on the neurological condition 
under consideration, as well as the specific classification of heart disease. Indeed, several putative mechanisms may relate NDs with CVD. NDs may cause a marked reduction in physical activity, increased stress, and disturbances in autonomic dysfunction. An alternative mechanism may relate to common medications used for treatment of NDs or for related secondary complications [8].

\section{Conclusion}

We report here an independent association between NDs and heart disease. Statistics Canada provides only the composite variable for these neurological conditions (with the exception of stroke and spinal cord injury), so we were not able to provide risk estimates for specific neurological disorders. Future studies should address this longitudinally, with specific NDs and classifications of heart disease to examine which conditions contribute to this observation, as well as explore potential mechanisms.

\section{Acknowledgments}

Study Funding: J. Cragg is supported by a University of British Columbia Killam Doctoral Scholarship and IODE War Memorial Doctoral Scholarship. J. Kramer is a Michael Smith Foundation for Health Research (MSFHR) and Rick Hansen Institute (RHI) Scholar. J. Borisoff is the Canada Research Chair in Rehabilitation Engineering Design.

\section{Disclosure Statement}

The authors report no disclosures (financial or otherwise) relevant to this manuscript.

\section{Author Contributions}

J. Cragg was responsible for the study concept/design, analysis/ interpretation of the data, and drafting the manuscript. J. Kramer was responsible for the study concept/design, interpretation of the data, and revising the manuscript for intellectual content. J. Borisoff was responsible for the study concept/design, interpretation of the data, and revising the manuscript for intellectual content.

\section{References}

Yekutiel M, Brooks ME, Ohry A, Yarom J, Carel R: The prevalence of hypertension, ischaemic heart disease and diabetes in traumatic spinal cord injured patients and amputees. Paraplegia 1989;27:58-62.

Cragg JJ, Noonan VK, Krassioukov A, Borisoff J: Cardiovascular disease and spinal cord injury: results from a national population health survey. Neurology 2013;81:723-728.

- 3 Wu JC, Chen YC, Liu L, Chen TJ, Huang WC, Cheng H, Tung-Ping S: Increased risk of stroke after spinal cord injury: a nationwide 4-year follow-up cohort study. Neurology 2012;78:1051-1057.

4 Cragg JJ, Noonan VK, Dvorak M, Krassioukov A, Mancini GB, Borisoff JF: Spinal cord injury and type 2 diabetes: results from a population health survey. Neurology 2013;81:1864-1868.

5 Statistics Canada: Canadian Community Health Survey (CCHS). http:// www23.statcan.gc.ca/imdb/p2SV.pl?Function=getSurvey\&SDDS=3226 (retrieved November 4, 2014).

6 D’Agostino RB Sr, Vasan RS, Pencina MJ, Wolf PA, Cobain M, Massaro JM, Kannel WB: General cardiovascular risk profile for use in primary care: the Framingham Heart Study. Circulation 2008;117:743-753.

7 Van der Kooy K, van Hout H, Marwijk H, Marten H, Stehouwer C, Beekman A: Depression and the risk for cardiovascular diseases: systematic review and meta analysis. Int J Geriatr Psychiatry 2007;22:613-626.

8 Erdoğan G, Ceyhan D, Güleç S: Possible heart failure associated with pregabalin use: case report. Agri 2011;23:80-83. 